\title{
ON-LINE MEASUREMENT OF QUALITY PARAMETERES OF BENTONITE BASED DRILLING MUDS
}

\author{
J. L. García-Siñeriz, J.L. Fuentes-Cantillana \\ AITEMIN. Alenza, 1. 28003 Madrid, Spain. \\ e-mail:sistemas@aitemin.es
}

\begin{abstract}
Different measurement systems have been developed for the automatic, on-line monitoring of the parameters that define the quality of the bentonite muds used in drilling and excavation works: Plastic viscosity, yield value, filter capacity, sand content, and ion content. These systems enable a continuous control of the mud characteristics, so that corrective actions can be taken immediately when deviations from specified ranges are observed.
\end{abstract}

Keywords: Bentonite, drilling mud, rheology, plastic viscosity, yield value, filter capacity, ion content.

\section{INTRODUCTION}

Bentonite-based muds are widely used in civil engineering, oil and gas exploration, mining, and other industries, as drilling fluid for the stabilisation of borehole and trenches walls during the excavation phase, to ensure the water tightness of the trench walls, and also to transport the rock debris from the cutting tool to the surface. However, the rheological characteristics of this type of muds, that make them most suitable for these functions, are adversely affected by different types of chemical contaminants, such as some ions (sulphates, $\mathrm{Ca} 2+, \mathrm{Fe} 3+$, heavy metals, ....) and organic matter (humics, hydrocarbons, ...). These components may be present in the rock formation and the ground water because of their natural chemical composition, or because of pollution.

In all cases, the control of the rheological characteristics of the mud is of major importance, as a contaminated mud must be corrected with chemical additives as soon as a deviation from the specifications is observed. Otherwise, the mud may become useless and must be replaced and treated as a waste material.

The control of the main properties of the mud (tyxotropy, filter cake, sand content, ..) is traditionally made by manual analysis, using the well known API procedures and test equipment. However, this type of analysis is slow, costly, and is difficult to perform at the site. These methods do not permit a continuous control nor a quick reaction in case of problems.
To solve this problem is one of the objectives of a research project titled "ECOMAT" (Ecological Construction Materials for Retention Barriers), which is being carried out by an international consortium composed by Soletanche-Bachy (France, Project Coordinator), Iko-Erbslöh (Germany), Ciments d'Obourg (Belgium), Aitemin (Spain), Trier University (Germany), and the Institut National Polytechnique de Lorraine (France). The project is being developed under the frame of the EC programme "Brite-EuRam". It started on January 1997 and will end by June 2000, and its general objectives are the optimization of the bentonite muds and the concrete-bentonite mixtures used in the construction of retention barriers for the confinement of contaminated soils. A detailed information about this project may be found in http://www.tra-efct.com (search for in "Cluster 8: New Technologies in Geotechnical Engineering")

The specific activity in the field of on-line monitoring of the quality of the bentonite mud has been focused in the following parameters:

- Rheology (plastic viscosity and yield value)

- Filter capacity

- Sand content

- Ions centent

The works carried out and the results obtained on each of these areas are briefly described below.

\section{TECHNICAL APROACH}

The main objective was to develop an integrated "measuring column" of the mud characteristics. This 
would be an special arrangement of sensing elements adapted to the plant operation conditions, designed under the basis of modularity and simple installation. This system should provide automatically the necessary on-line measurement of the mud physical and chemical parameters which are relevant for the optimal control of the mud cycle in the on-site processing plants.

The technical approach followed to achieve this aim is of a stepwise type:

- When possible, to use sensors already available in the market which could be directly applied in this problem, with minor or no modifications.

- When applicable, to adapt sensors or sensing techniques which are used in other types of applications but could also be used in this one by introducing modifications or developing special attachments and/or utilisation methods.

- When no other options exist, to develop new sensing systems.

The technical progress achieved during the development of this work can be summarised as follows:

\section{RHEOLOGIC PROPERTIES}

A new system (on-line viscometer), based on measurement of the pressure loss of the mud of a fluid in a determined length of pipe depending on the flow rate $Q$, has been developed. Detailed analyses have been carried out to determine the dimensions of the measuring pipe and flow rates necessary to calculate the Plastic viscosity \& Yield Point .

The obtained results show that the system, after making the adequate adjustments, provides an

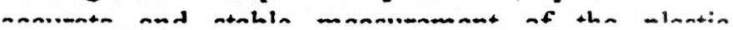
1/2 62 wh wh MAR c/avena FANN: P.V: 8, Y.Y.: 13,5

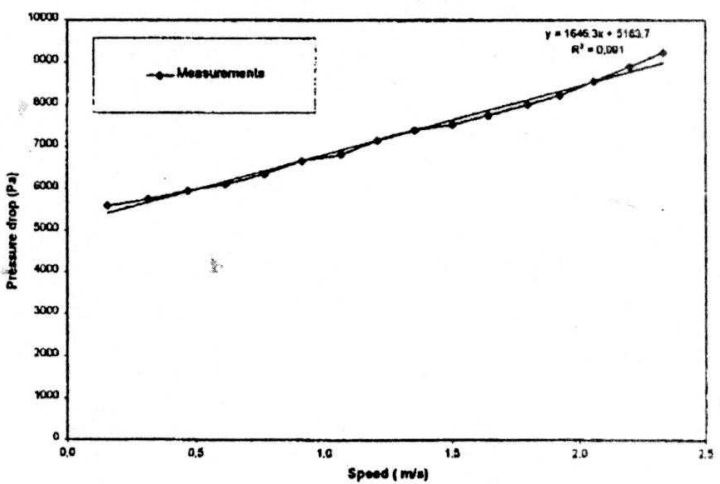

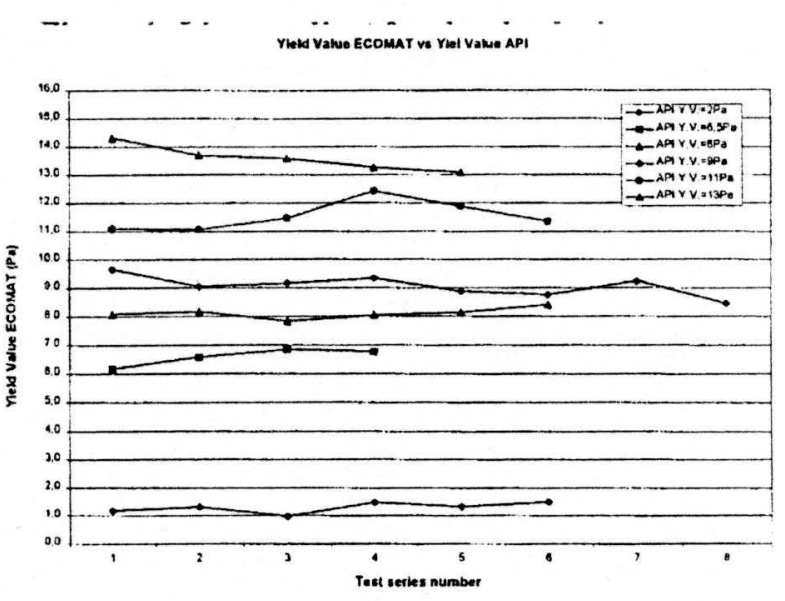

Figure 2: Rheologic properties results (Plastic viscosity)

(NOTE: For V.P. $=6 \mathrm{mPa}$ the fitting is out of standard linear conditions)

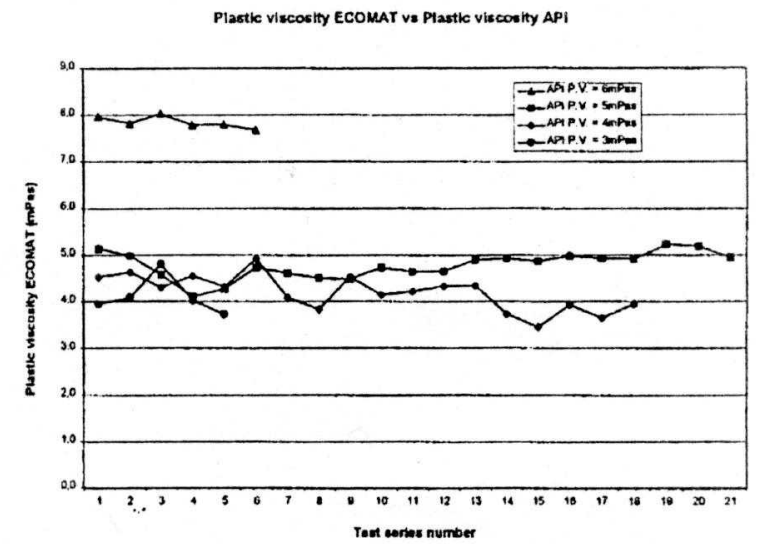

Figure 3: Rheologic properties results (Yield value)

\section{FILTER PROPERTIES \& SAND RATE}

A new type of measuring chamber (called 'ECOMAT chamber") has been designed and constructed. That chamber is based on the same principle as the API low temperature and lowpressure filtration test. The function of this chamber is to automatically measure the mud characteristic cake thickness and filtrate volume. It can also be used to measure the sand rate by just changing the filter type. 
The correlation tests indicate that the ECOMAT chamber gives accurate and stable measurement for the mud filter properties and sand rate, after an adequate adjustment.

The tests carried out show that the cake thickness reading obtained with the ECOMAT chamber is exactly the same one as that in the API reference test.

The volume of filtrate versus time is different because the filter characteristics are not the same, but a good and constant correlation has been identified between both systems, as shown in Figure 4 for different test pressure conditions.

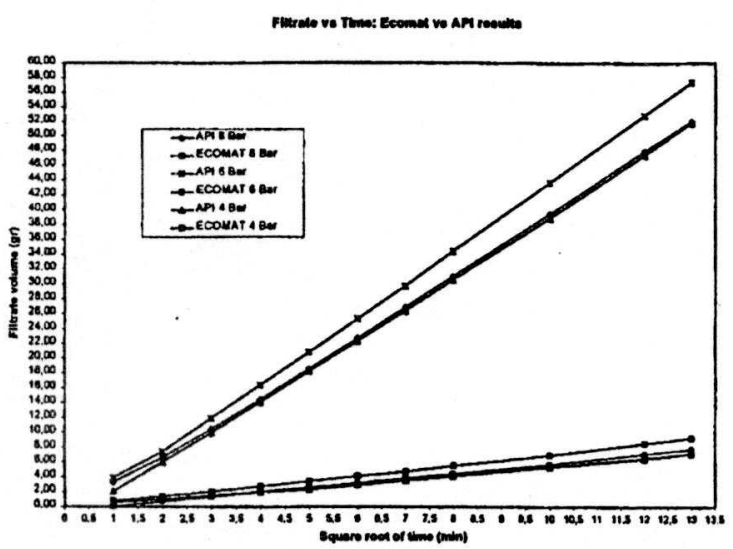

Figure 4: Filtrate response (Ecomat chamber vs API test)

Results from the performed tests show that the ECOMAT chamber can provide a good measurement of the ratio of solids (volume percentage) contained in mud.

\section{ION CONTENT}

The market search on available sensors for the on-line measurement of ion content (calcium, sulphate, chloride, magnesium, and sodium) enabled the identification of a number of potentially applicable sensors and techniques. The techniques finally considered are:

- Colorimetric analyzers.

- Tritators.

- Ion selective electrodes.

- Ultraviolet absorption analysis.

After a technical and economical analysis of these, the ion selective electrode method was selected as the best option, for cost and simplicity reasons. An on-line measuring scheme for ion contents, based on ion selective electrodes, has been designed and assembled.

All developed measuring trials confirm that ion selective electrodes may be applied for the on-line measurement of mud ion content in: calcium, chloride and sodium. Also good enough results have been got for the magnesium content.

Table I shows a brief summary of the main characteristics of the used electrodes.

The conclusion obtained after the tests carried out is that ion selective electrodes give a better response (more accurate) when mounted on-line in the mud circuit than in the lab tests, because the mud is more homogeneous (better water/bentonite mixing) and the mud flow is more stable too.

\begin{tabular}{|c|c|c|c|}
\hline Electrode & Type & $\begin{array}{c}\text { Reproducti } \\
\text { bility }\end{array}$ & $\begin{array}{c}\text { Concentration } \\
\text { Range }\end{array}$ \\
\hline Chloride & Solid-state & $\pm 2 \%$ & $\begin{array}{c}1.8 \text { to } 35500 \\
\mathrm{ppm}\end{array}$ \\
\hline Sodium & Glass & $\pm 2 \%$ & $\begin{array}{c}\text { Saturated to } \\
0.02 \mathrm{ppm}\end{array}$ \\
\hline Calcium & $\begin{array}{c}\text { Plastic } \\
\text { membrane }\end{array}$ & $\pm 4 \%$ & $\begin{array}{c}0.02 \text { to } 40100 \\
\text { ppm } \mathrm{Ca}^{2+}\end{array}$ \\
\hline $\begin{array}{l}\text { Divalent } \\
\text { (water } \\
\text { hardness) }\end{array}$ & $\begin{array}{c}\text { Plastic } \\
\text { membrane }\end{array}$ & $\pm 4 \%$ & $\begin{array}{c}0.2 \text { to } 40100 \\
\mathrm{ppm} \mathrm{Ca}^{2+}\end{array}$ \\
\hline
\end{tabular}

Table I: Ion Selective Electrodes (ISE) Characteristics.

Figure 5 shows the response of these electrodes during some of the on-line test in comparison with their measurement in the water filtrate from mud samples taken from the test bench flow.

CHLORIDE
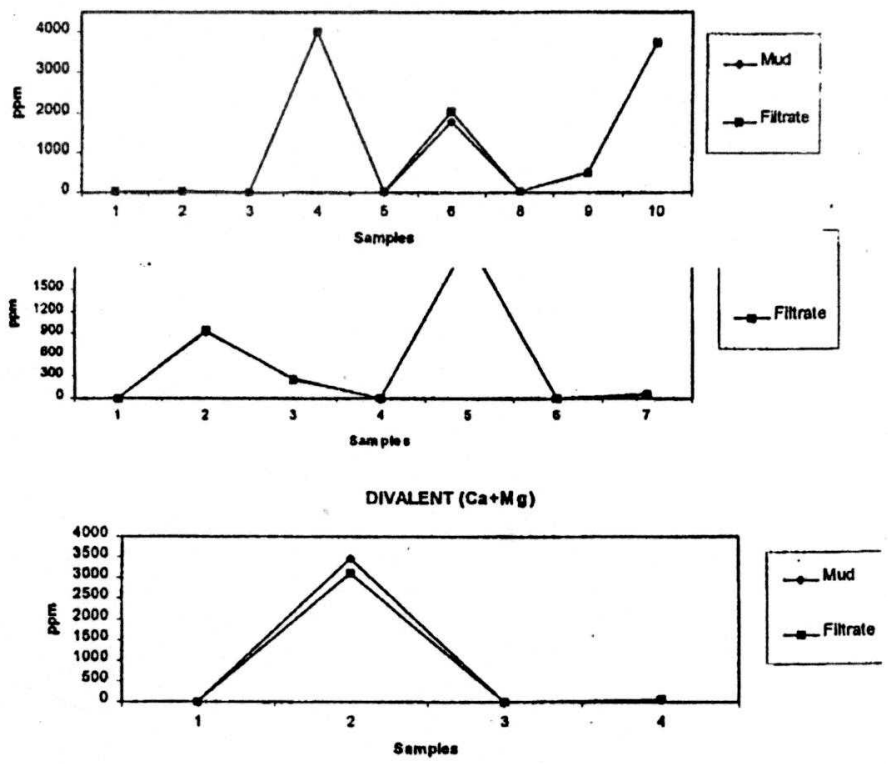

Figure 5: Ion Selective Electrodes measurement result. 


\section{MEASURING COLUMN}

The obtained measuring column consists in three independent modules linked by a switching panel, which distributes mud or clean water to each one depending on measuring cycles and running periods:

- Module 1: Rheological properties determination.

- Module 2: Ecomat chambers (Filtration properties \& sand rate).

- Module 3: Ions content determination.

Each module has been designed to work independently from the others. The final designs also include improvements from the original ones used in the preliminary evaluation test, for a better adaptation to the work site environment, including self cleaning and maintenance routines. In the case of the ion determination module, a climatic regulation system has been adapted to the measuring cabinet.

As example, Photograph 1 shows how the ECOMAT chamber for determination of filtration properties, after being automated and integrated in the measuring column.

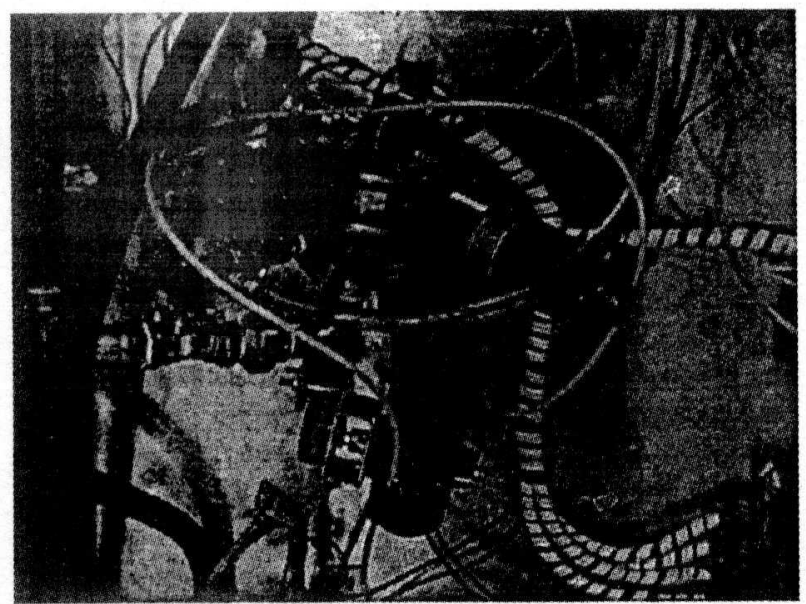

Photograph 1: Ecomat chamber for determination of filtration properties

The module for the determination of ions content (Module 3) is shown in Photograph 2.

\section{DATA ACQUISITION AND CONTROL}

The measuring column is managed by a computer (AITEMIN PC), which will be linked by a local network with an Expert System running in another computer (SOLBAC PC).

All controllable elements of the column (pumps, valves, etc) as well as the measuring sensors installed, have been adequately wired to interface boards linked to the data acquisition and control cards plugged in the AITEMIN PC (see Figure 6 and Photograph 3).

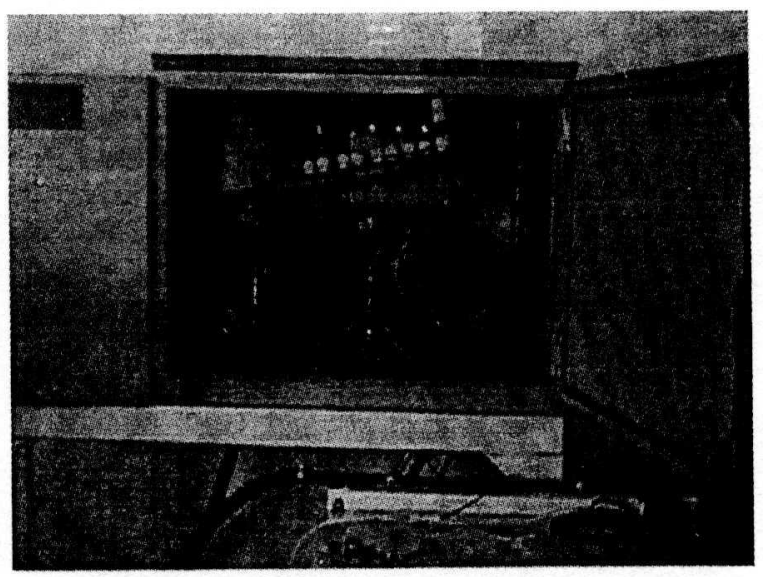

Photograph 2: Module for the determination of ions content.

The acquisition and control program has been built in Visual $\mathrm{C}++$, running under Windows 95 . It performs the adequate control of the modules and gathers the data provided by the sensors.

The input/output scan rate is $1 \mathrm{~Hz}$ minimum. The process control has been branched in four different close loops running in parallel, one for each module control plus one for the electrodes cabinet temperature control. Test and cleaning routines have been included in all processes.

The data obtained by the data acquisition and control program is presented on the $\mathrm{PC}$ screen in real time and the data file refreshed every 15 minutes. When linked to the Expert System, the Measuring Column PC obtains the data from the mud at periods defined by the Expert System, this enables to automatically increment the measuring frequencie: when changes in the mud properties are detected.

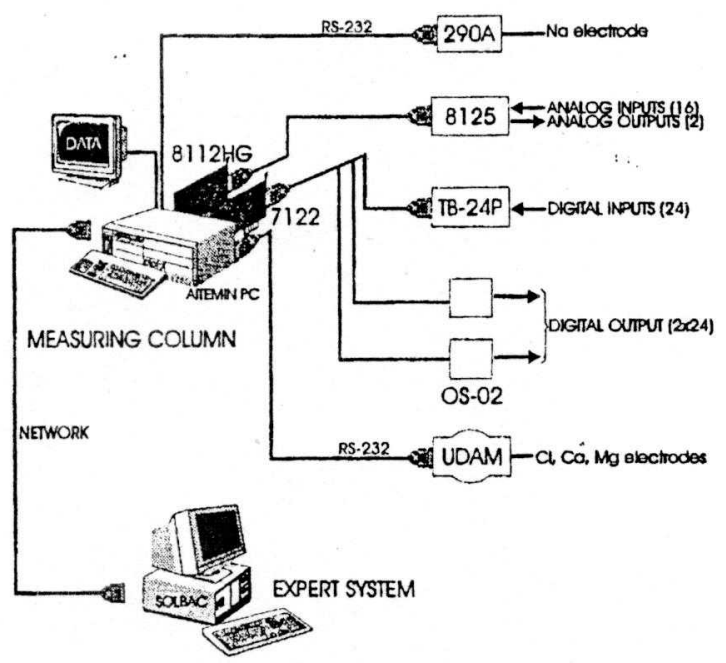


Figure 6: General architecture of the data

acquisition and control system.

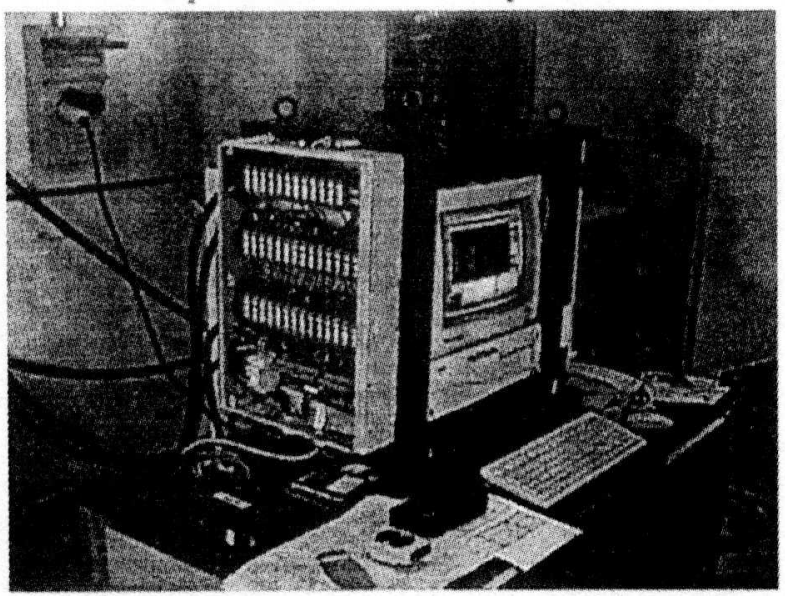

Photograph 3: Measuring column PC during evaluation tests.

\section{CONCLUSIONS}

s

In general, the results obtained fulfil the project objectives. Extensive "validation tests have been carried out in the lab, and the field tests are planned for the last quarter of 1999.

In parallel, the patent process has been started for some specific developments, as for instance the use of the ECOMAT chamber as a new system for the on-line determination of the filtration properties and the sand rate of drilling fluids.

\section{Acknowledgments}

The authors want to express their gratitude to the other partners of the ECOMAT project by its permission and support to publish this paper, and by the excellent collaboration experienced along all the project development. 